\title{
Micro Mechanical Measurement of Concrete Strain to Evaluate Principal Strain Distribution in RCC Moderate Deep Beams across its Width and Depth
}

\author{
Vinu R. Patel ${ }^{1}$, Dr. I. I. Pandya ${ }^{2}$ \\ ${ }^{\text {I}}$ (Assistant Professor, Department of Applied Mechanics, Faculty of Technology \& Engineering, M.S. \\ University, Baroda, 390020, Gujarat, India) \\ ${ }^{2}$ (Associate Professor, Department of Applied Mechanics, Faculty of Technology \& Engineering, M.S. \\ University, Baroda, 390020, Gujarat, India)
}

\begin{abstract}
This paper investigates the distribution of principal strain by micro mechanical measurement of concrete axial strain in Reinforced Cement Concrete (RCC) moderate deep beams across its width and depths for various span-to-depth ratios. A complete shear deformational behavior along with load-deflection response, crack patterns and modes of failure were studied experimentally. Twelve beams were tested and results of principal strain were plotted. Nature of principle tensile strain distribution was found similar to elliptical pattern of distribution along the line joining the load and the support point. The assumption of plane stress condition underestimates the significance of the small compressive or tensile stresses develop in the transverse direction from incompatible response of consecutive concrete elements subjected to different states of stress. Therefore, it was considered that the modes of shear failure are associated with multi-axial stress conditions which exist in the region of the paths along which the compressive forces are transmitted to the supports.
\end{abstract}

Keywords:-Reinforced concrete, Moderate deep beams, Principal strain distribution.

\section{INTRODUCTION}

As per IS: $456^{[1]}$, beams can be classified into three categories namely normal or shallow beams, moderate deep beams, and deep beams. These classifications are based on their span-to-depth or shear span(a)to-depth(D) ratio. In general, it can be classified as Shallow beams ( $\ell / D \geq 6.0$ or a/D $>2)$, Moderate deep beams $(2.0<\ell / D<6.0$ or $1.0<\mathrm{a} / \mathrm{D}<2)$ and Deep beams $(0.5<\ell / D \leq 2.0$ or a/D $<1.0)$. Moderate deep beams and deep beams have a wide application in structural engineering field. Numerous investigations have been carried out and reports were published regarding the strength and the load-deformation behavior of moderate deep and deep beams ${ }^{[2],[3],[4]}$. A very little works have been reported on shear deformational behavior of RCC moderate deep beams, particularly, related to the study of principal strain distribution. Moderate deep and deep beams are shear predominant members and generally fail in brittle shear mode ${ }^{[5],[6]}$. Hence the study of strain deformational behavior is an important step towards the deeper understanding of behavior of beams under applied loading.

It is essential to know the complete load-deformational behavior before design of any structure. The complete and careful analysis is required to predict the behavior of any structure. Micromechanical measurement and analysis of an individual structural element is very important for prediction of complex behavior of structure such as its loading capacity, rotational capacity, strain deformational behavior and cracking mechanism activated under applied loading.

In the present investigation, Visualization was made regarding the distribution of principal strain in shear zone and variation of the same along the line joining the load and the support point. The shear capacity of RCC section can be determined by addition of shear resistance offered by two components namely concrete and reinforcement. Shear capacity of concrete depends on splitting of an elliptical section whose major axis lies on the line joining the load and support point. The nature of strain distribution along this inclined axis was found similar to elliptical section (Fig. 5) as described above. The prime aim was to provide a systematic and comprehensive study on the shear deformational behavior and principal strain distribution in RCC moderate deep beams using simple instrumentation approach. An innovative hexagonal grid arrangement of Demec targets considering triangular rosette pattern (Fig. 3) was used to measure the concrete axial strain. Evaluation of principal strain from concrete axial strain readings using Mohr's circle diagrams confirms the strain distribution along the inclined axis joining the load and support points. 


\section{OBJECTIVE}

The objective of the present experimental investigation was to micro mechanically measure the concrete axial strain in the shear span to evaluate principal strain distribution in RCC moderate deep beams across its width and depths to obtain the clear information regarding the strain distribution at various planes, which provides deeper understanding of the fundamental nature of shear behavior during the pre cracking stage, at the time of crack initiation and during the post cracking stage.

\subsection{Test materials}

\section{EXPERIMENTAL PROGRAMME}

Ordinary Portland cement of 53 grade having compressive strength of $53 \mathrm{~N} / \mathrm{sq} . \mathrm{mm}$ at 28 days, Initial setting time 31 Minutes and final setting time of 600 minutes, Standard consistency of $30 \%$ was used. Natural river sand having fineness modulus of 2.8 , Specific gravity of 2.65 , bulk density of $1470 \mathrm{~kg} / \mathrm{Cu} . \mathrm{M}$ and maximum size of $4.75 \mathrm{~mm}$ was used as a fine aggregate. Natural basalt gravel of maximum size $20 \mathrm{~mm}$, Specific gravity of 2.85 , fineness modulus of 6.85 , and bulk density of $1320 \mathrm{~kg} / \mathrm{Cu} . \mathrm{M}$ was used as coarse aggregate were used. The concrete mix proportion was 1:1.5:3.0 (cement: fine aggregate: coarse aggregate) by weight with water cement ratio of $0.45 \mathrm{kept}$ constant for all beams. The ingredients used in the concrete were $436.4 \mathrm{~kg} / \mathrm{Cu} . \mathrm{M}$ Cement, $654.6 \mathrm{~kg} / \mathrm{Cu} . \mathrm{M}$ sand and $1309.2 \mathrm{~kg} / \mathrm{Cu} . \mathrm{M}$ as a Coarse Aggregate with $2400 \mathrm{~kg} / \mathrm{Cu} . \mathrm{M}$ density of concrete. Longitudinal tension reinforcement consists of High yield strength deformed bars ( $\mathrm{Fe} 415)$, while vertical web reinforcement (stirrups) consists of mild steel bars (Fe 250) of $6 \mathrm{~mm}$ diameter placed at $100 \mathrm{~mm} \mathrm{c} / \mathrm{c}$ throughout as shown in figure 1. There were four series of beams having different depths of $300 \mathrm{~mm}, 400 \mathrm{~mm}$, $500 \mathrm{~mm}$ and $600 \mathrm{~mm}$ with three beams in each series. For each series six cubes $(150 \mathrm{~mm})$ and eight cylinders (four cylinders for compressive strength and four cylinders for splitting strength, $150 \mathrm{~mm}$ diameter and $300 \mathrm{~mm}$ height) were cast as control specimens. All specimens were cured at least for 28 days. Table 1 shows the results of control specimen after 28 days of curing.

\subsection{Specimen Details}

Testing was carried out on twelve beams, simply supported on constant effective span of $1200 \mathrm{~mm}$ under two point concentrated symmetrical loads as shown in figure 2. All the beams were having constant overall span and width of $1300 \mathrm{~mm}$ and $150 \mathrm{~mm}$ respectively. There were four series of beams having different depths of $300 \mathrm{~mm}, 400 \mathrm{~mm}, 500 \mathrm{~mm}$, and $600 \mathrm{~mm}$. Each series comprised of three beams having same depth. The concrete axial strain was measured through holes made having various depths of $0.0 \mathrm{~mm}, 50 \mathrm{~mm}$, and 75 $\mathrm{mm}$ across the width of the beams. The beam notation "D60 S 5.0" denotes the beam having overall depth D of $60 \mathrm{~cm}$ and concrete axial strains are measured on the points at a depth of $5.0 \mathrm{~cm}$ across the width of the beam from surface plane.

\subsection{Testing Procedure}

After completion of curing for 28 days, surface of specimen was made smooth by removing projection if any. All the beams were white washed to visualize the marking and cracks on the surface of beam. The beams were tested under gradually applied two point down load on Universal Testing machine (UTM) having $200 \mathrm{~T}$ capacity as shown in figure 2. Beams were centered on platform and leveled horizontally and vertically using level tube by adjusting the bearing plates. Before testing it is necessary to fix the DEMEC points on the surface or in depth by proper adhesive, which guides the pointer of strain gauge. Figure 3 shows the grid arrangement of DEMEC targets on beam. As per that grid, $10 \mathrm{~mm} \emptyset$ hollow aluminum discs are fixed as a DEMEC targets to measure the strain. The Concrete strains were measured on planes situated at different depths of $2.5 \mathrm{~cm}, 5.0 \mathrm{~cm}$, and $7.5 \mathrm{~cm}$ across the width of the beam from the surface. The mechanical type DEMEC gauges having knife edges of different lengths of $2.5 \mathrm{~cm}, 5.0 \mathrm{~cm}$, and $7.5 \mathrm{~cm}$ were used to measure strain at every interval of loading. Initiation or appearance and propagation of cracks, first cracking and ultimate loads, and modes of failure of beam were noted as shown in Table $2 \&$ Table 3. At every stage of loading, the process of detecting and marking of new cracks and measuring the propagation of all cracks were continued up to the failure of the beam. Crack propagations were traced by pencil and their tips were marked corresponding to the load readings. Principal strains are calculated from concrete axial strains by triangular rosette and Mohr's circle diagrams.

\subsection{Crack Patterns, Propagation, and Modes of Failure}

\section{DISCUSSION OF TEST RESULTS}

In all the beam specimens, initiation of flexure cracks (Fig. 4) was from the bottom of the beams. In most of the cases, all the flexure cracks were almost vertical, while most of the shear cracks (Fig. 4) were inclined and their direction of propagation was towards the nearest load point irrespective of its place of origin.

Beams of series D30 (shallow /normal beams) failed in pure flexure failure by yielding of longitudinal tensile reinforcement. Size and propagation of the flexure cracks were noticeable, while shear cracks were few 
and very fine. Majority of flexure cracks (Fig. 4) propagated beyond 3/4 height of the beam and were considerably wide at the bottom.

Beams of series D40 and D50 (moderate deep beams) failed in flexure-shear mode. The phenomenon of all of a sudden formation of major diagonal shear cracks emerging from D/3 to D/4 height of the beam from bottom and its rapid propagation towards the nearest load and support point; was firstly seen in beams of D50 series. Although, the shear cracks were comparable to flexure cracks; the ultimate failure of all the beams of D40 \& D50 series was due to the yielding of the longitudinal tensile reinforcement.

Beams of series D60 (deep beams) failed in pure shear failure as shown in Fig. 4. Flexure cracks were few and very fine, and hardly reached up to the mid height of the beam, while shear cracks were noticeable in size and its propagation covered more than $3 / 4$ height of the beam. After sudden formation of major diagonal shear cracks (Fig. 4) beam sustained some more load before ultimate failure, which shows its reserve strength. Table $2 \&$ Table 3 shows the value of First crack load, Ultimate load, deflection, ductility, reserved strength and modes of failure for all D30 to D60 series of beams for different $\mathrm{a} / \mathrm{D}$ ratio where $\mathrm{a}=$ shear span and $\mathrm{D}=$ overall depth of beam. Table 4 shows the value of principal tensile strains along the inclined axis 8-12-16 for D50 beam for different value of load applied at an interval of $2 \mathrm{~T}$.

We have not observed any appreciable change in the value of strains across the width of beam. Minor changes in the value of strains observed may be due holes made on the surface across the width to measure the strain at $2.5 \mathrm{~cm}, 5.0 \mathrm{~cm}$ and $7.5 \mathrm{~cm}$ from the surface.

\section{CONCLUSION}

In majority of beams of series D50 and D60 i.e. moderate deep beams and deep beams; the major diagonal shear cracks were formed all of a sudden. These cracks were initiated by splitting action and the phenomenon of failure was similar to that of cylinder under diametrical compression in split cylinder test. These cracks were emerged from $\mathrm{D} / 3$ to $\mathrm{D} / 4$ height of the beam from bottom and rapidly extended towards nearest load and support points. The plots (Fig. 5) of evaluated results of principal tensile strain along the inclined axes in the vicinity of the diagonal shear cracks formed along the line joining the load and support points reveals the strain distribution similar to the elliptical pattern. Graphs (Fig. 5) were plotted assuming a zero value of principal tensile strain at the top and bottom most edges of the beams. This phenomenon is consistent with the theoretical and experimental observations reported by F.K. Kong and others. Behavior of Beam D30 was like shallow beams where failures were due to flexure. Beam of D40 and D50 series behaves like Moderate deep beam where failures were due to combined flexure and shear. Beam of D60 series behaves as a deep beam where failure was due to pure shear.

\section{Indian Code:}

\section{REFERENCES}

[1]. IS 456: 2000, "Plain and Reinforced Concrete - Code of Practice”, Fourth Revision, BUREAU OF Indian STANDARDS (BIS 2000), Fifth Reprint August 2002

\section{Journal Papers:}

[2]. KONG F.K., Reinforced Concrete Deep Beams, First Edition, Blackies and Son Ltd., Glasgow and London, Published by Van Nostrand Reinhold, New York, June 1990.

[3]. KOTSOVOS MICHAEL D., Behavior of Reinforced Concrete Beams with a shear span-to-Depth Ratio Between 1.0 and 2.5, Title no.81-27, ACI Journal, V.81, No.3, May-June 1984, p.p.279-286.

Theses:

[4]. PATEL S.N., and DAMLE S.K., Behavior of Reinforced Concrete deep Beams in flexure and shear, PhD Thesis, The M. S. University of Baroda, December 1976.

Journal Papers:

[5]. RAMKRISHNAN V. and ANANTHARAYANA Y., Ultimate Strength of Deep Beams in Shear, ACI Journal Proceedings, V.65, No.2, February 1968.

[6]. KIM WOO, and WHITE, RICHARD N., "Initiation of Shear Cracking in Reinforced Concrete Beams with No Web Reinforcement”, Title no. 88-S32, ACI Structural Journal, V. 88, No. 3, May-June 1991, pp. 301-308 
Table 1

\begin{tabular}{|c|c|c|c|c|c|}
\hline BEAM & $\begin{array}{c}\text { CONCRETE } \\
\text { MIX by } \\
\text { weight } \\
\text { proportion }\end{array}$ & $\begin{array}{c}\text { WATER } \\
\text { CEMENT } \\
\text { RATIO }\end{array}$ & $\begin{array}{c}\text { AVERAGE } \\
\text { CUBE } \\
\text { COMPRESSIVE } \\
\text { STRENGTH } \\
\left(\mathbf{N} / \mathbf{m m}^{\mathbf{2}}\right)\end{array}$ & $\begin{array}{c}\text { AVERAGE } \\
\text { CYLINDER } \\
\text { COMPRESSIVE } \\
\text { STRENGTH } \\
\left(\mathbf{N} / \mathbf{m m}^{\mathbf{2}}\right)\end{array}$ & $\begin{array}{c}\text { AVERAGE } \\
\text { SPLIT } \\
\text { CYLINDER } \\
\text { STRENGTH } \\
\left.\text { (N/mm }^{\mathbf{2}}\right)\end{array}$ \\
\hline D30 & $1: 1.5: 3$ & 0.45 & 33.20 & 26.40 & 3.70 \\
\hline D40 & $1: 1.5: 3$ & 0.45 & 31.30 & 26.10 & 3.58 \\
\hline D50 & $1: 1.5: 3$ & 0.45 & 32.10 & 25.80 & 3.55 \\
\hline D60 & $1: 1.5: 3$ & 0.45 & 34.30 & 27.40 & 3.75 \\
\hline
\end{tabular}

Table 2

\begin{tabular}{|c|c|c|c|c|c|}
\hline BEAM & $\begin{array}{c}\text { FIRST CRACK } \\
\text { LOAD }\end{array}$ & $\begin{array}{c}\text { ULTIMATE } \\
\text { LOAD }\end{array}$ & $\begin{array}{c}\text { DEFLECTION } \\
\text { AT FIRST } \\
\text { CRACK } \\
\text { LOAD }\end{array}$ & $\begin{array}{c}\text { DEFECTION } \\
\text { AT } \\
\text { ULTIMATE } \\
\text { LOAD }\end{array}$ & DUCTILITY \\
\cline { 2 - 6 } & $(\mathrm{t})$ & $(\mathrm{t})$ & $\delta_{\mathrm{y}}(\mathrm{mm})$ & $\delta_{\mathrm{u}}(\mathrm{mm})$ & $\delta_{\mathrm{u} / \delta_{\mathrm{y}}}$ \\
\hline D30 & 6.00 & 16.1 & 0.67 & 5.98 & 8.93 \\
\hline D40 & 10.10 & 29.5 & 0.43 & 3.80 & 8.84 \\
\hline D50 & 19.60 & 46.2 & 0.94 & 5.70 & 6.06 \\
\hline D60 & 21.60 & 55.6 & 1.00 & 5.43 & 5.43 \\
\hline
\end{tabular}

Table 3

\begin{tabular}{|c|c|c|c|c|c|c|}
\hline BEAM & $\begin{array}{c}\text { L/D } \\
\text { RATIO }\end{array}$ & $\begin{array}{c}\text { a/D } \\
\text { RATIO }\end{array}$ & $\begin{array}{c}\text { FIRST } \\
\text { CRACK } \\
\text { LOAD }\end{array}$ & $\begin{array}{c}\text { ULTIMATE } \\
\text { LOAD }\end{array}$ & $\begin{array}{c}\text { RESERVED } \\
\text { STRENGTH }\end{array}$ & Mode of failure \\
\cline { 3 - 6 } & & $\mathrm{Wc}(\mathrm{t})$ & $\mathrm{Wu}(\mathrm{t})$ & $\begin{array}{c}(\mathrm{Wu}-\mathrm{Wc}) / \mathrm{Wc} \mathrm{x} \\
100\end{array}$ & \\
\hline D30 & 4.00 & 1.33 & 6.00 & 16.10 & 168.33 & Flexure \\
\hline D40 & 3.00 & 1.00 & 10.10 & 29.50 & 192.08 & Flexure-shear \\
\hline D50 & 2.40 & 0.80 & 19.60 & 46.00 & 134.69 & Flexure-shear \\
\hline D60 & 2.00 & 0.67 & 21.60 & 55.60 & 157.40 & Shear \\
\hline
\end{tabular}

Table 4

\begin{tabular}{|c|c|c|c|c|c|c|c|c|c|c|c|c|c|}
\hline \multicolumn{14}{|c|}{$\begin{array}{l}\text { PRINCIPAL TENSILE STRAIN VARIATION ALONG INCLINED AXIS 8-12-16 } \\
\text { IN BEAM D50 RCC }\left(\times 10^{-6}\right)\end{array}$} \\
\hline DEPTH & SHEAR & $0.0 \mathrm{t}$ & $2.0 \mathrm{t}$ & $4.0 \mathrm{t}$ & $6.0 \mathrm{t}$ & $8.0 \mathrm{t}$ & $10.0 \mathrm{t}$ & $12.0 \mathrm{t}$ & $14.0 \mathrm{t}$ & $16.0 \mathrm{t}$ & $18.0 \mathrm{t}$ & $20.0 \mathrm{t}$ & $22.0 \mathrm{t}$ \\
\hline 560 & & 0 & 0 & 0 & 0 & 0 & 0 & 0 & 0 & 0 & 0 & 0 & 0 \\
\hline 380 & 8 & 0 & 115 & 230 & 346 & 461 & 576 & 691 & 807 & 922 & 1220 & 1626 & 2276 \\
\hline 280 & 12 & 0 & 150 & 300 & 450 & 616 & 766 & 916 & 1086 & 1336 & 2045 & 2281 & 2542 \\
\hline 180 & 16 & 0 & 132 & 263 & 395 & 526 & 658 & 789 & 994 & 1557 & 2744 & 3027 & 3356 \\
\hline 0 & & 0 & 0 & 0 & 0 & 0 & 0 & 0 & 0 & 0 & 0 & 0 & 0 \\
\hline
\end{tabular}



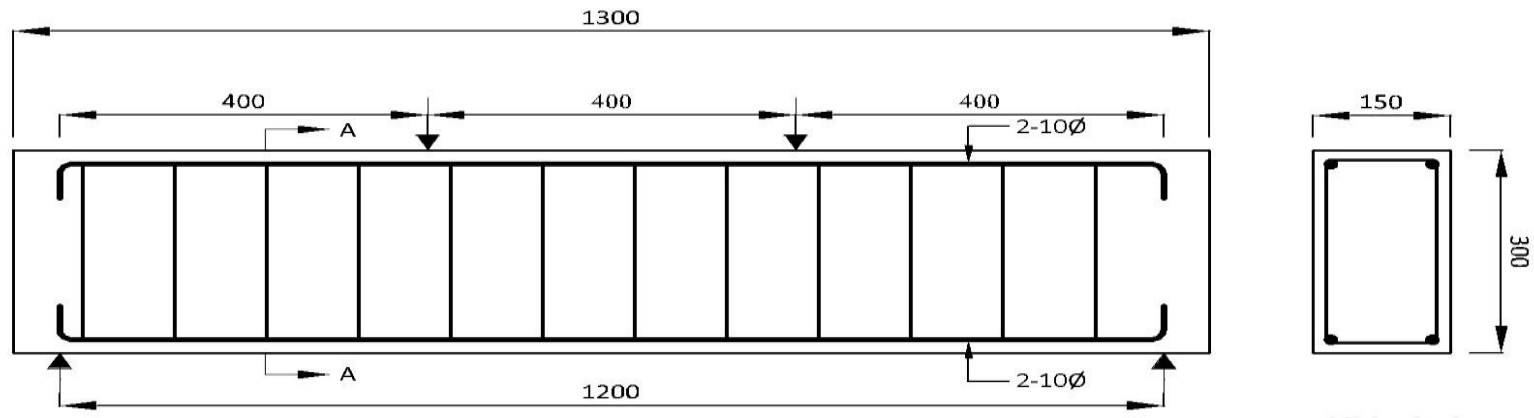

SEC. A-A
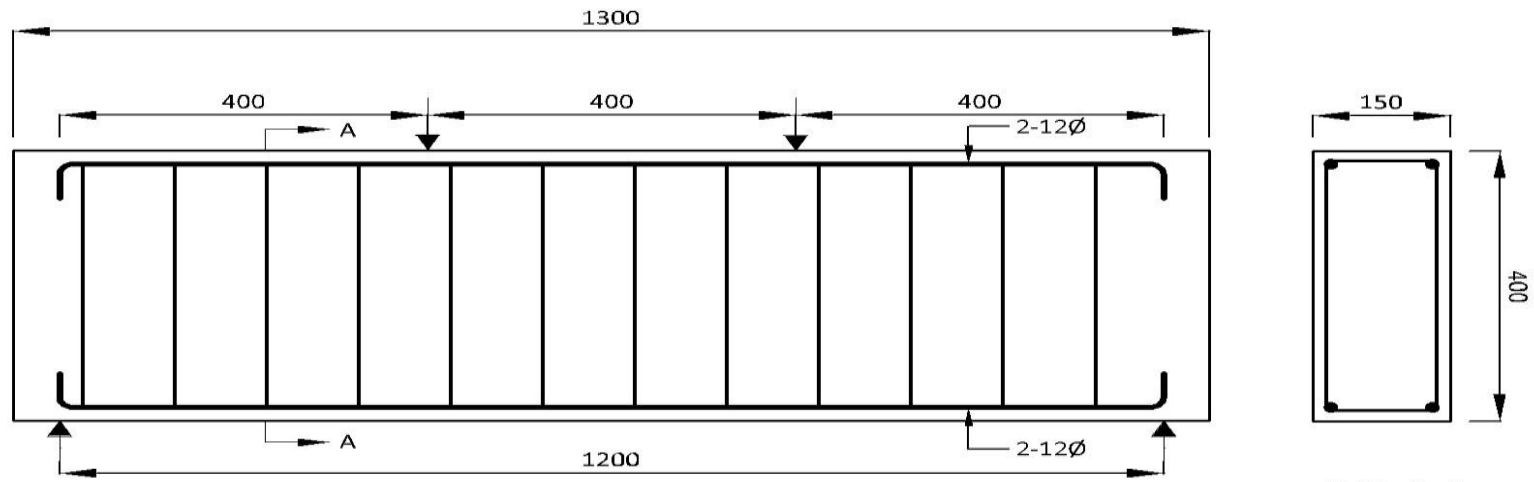

SEC. A-A
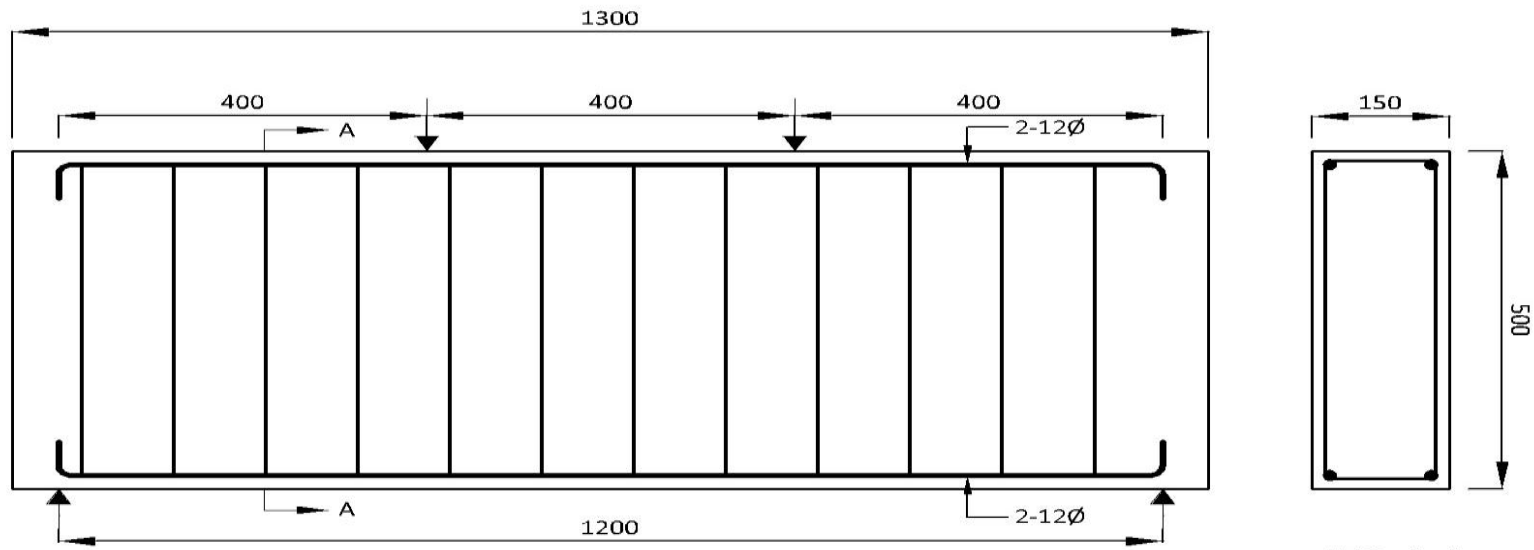

SEC. A-A
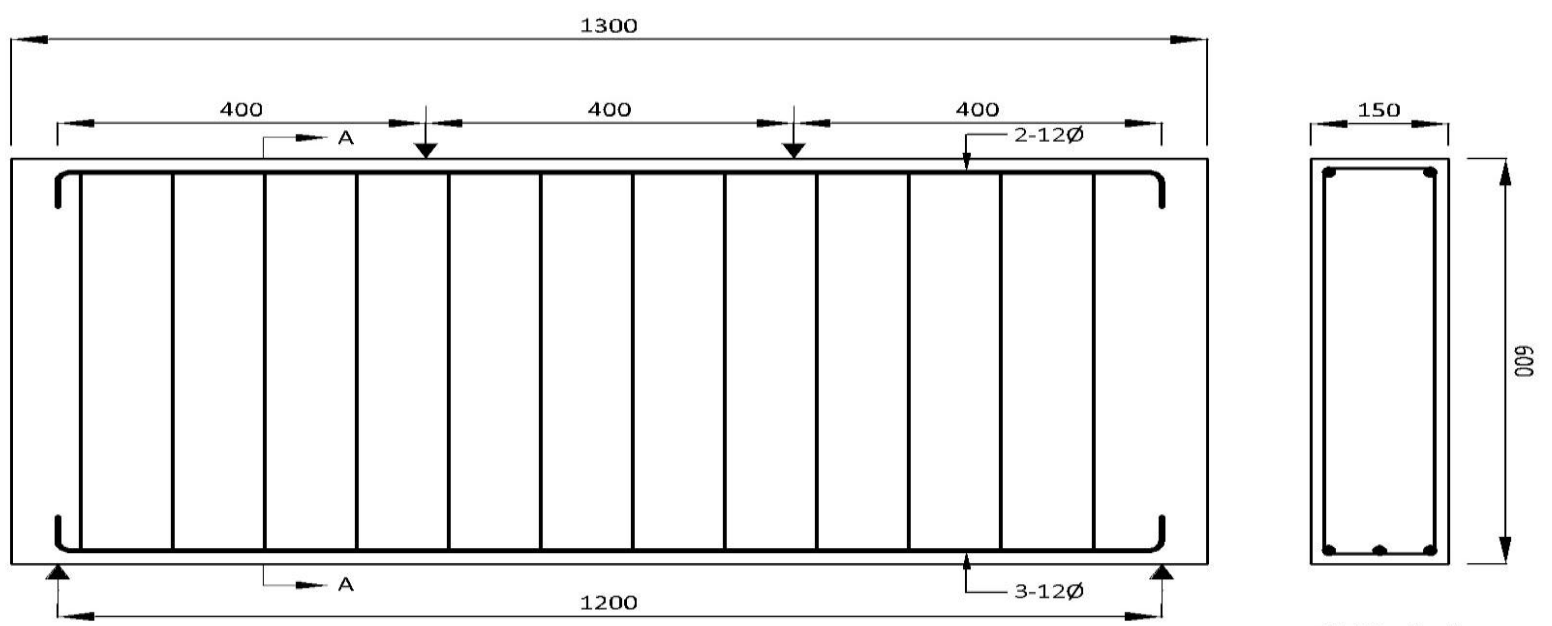

Fig. 1 Reinforcement detail of Moderate Deep Beam

SEC. A-A 


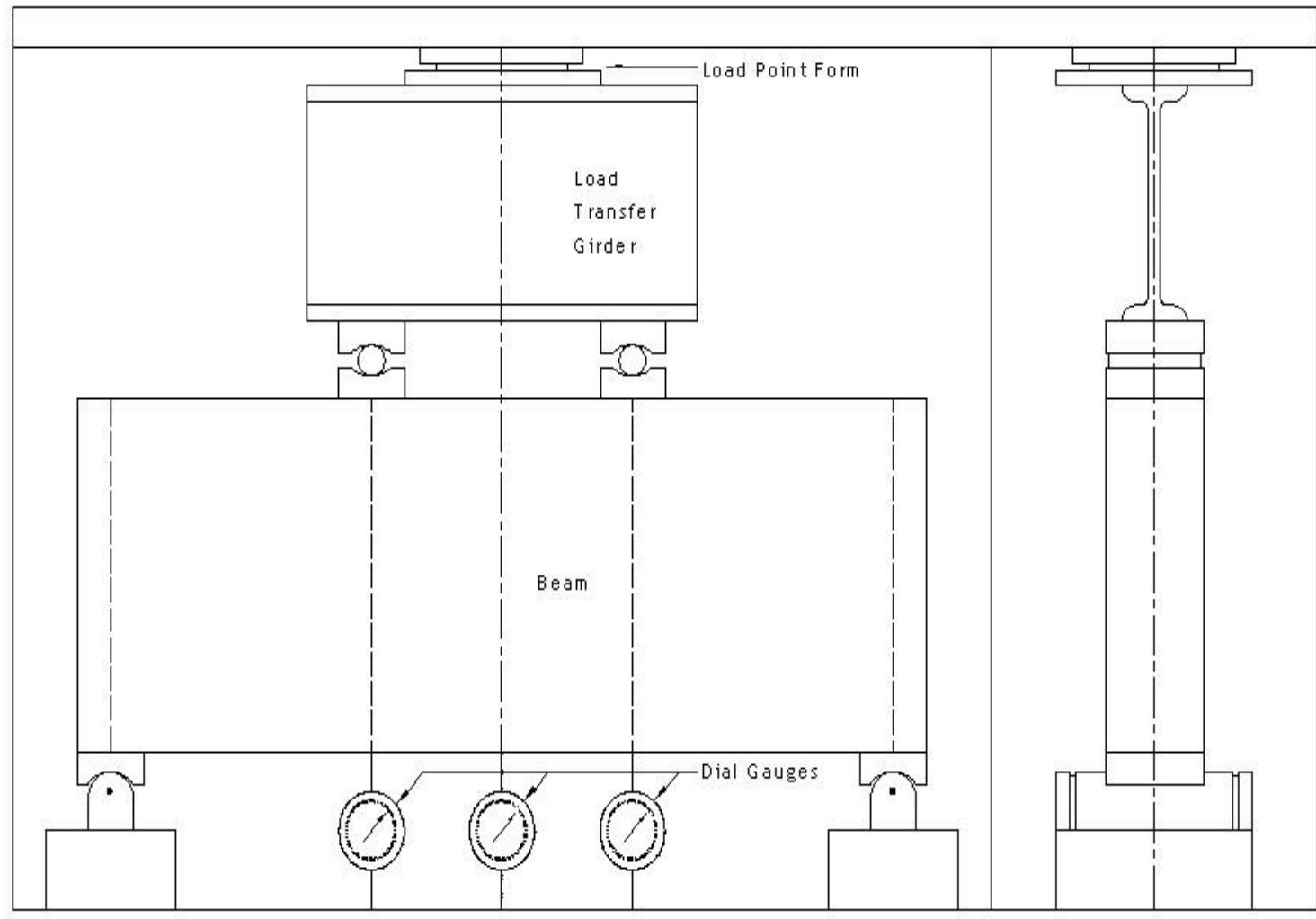

Fig. 2 Test Load Arrangement

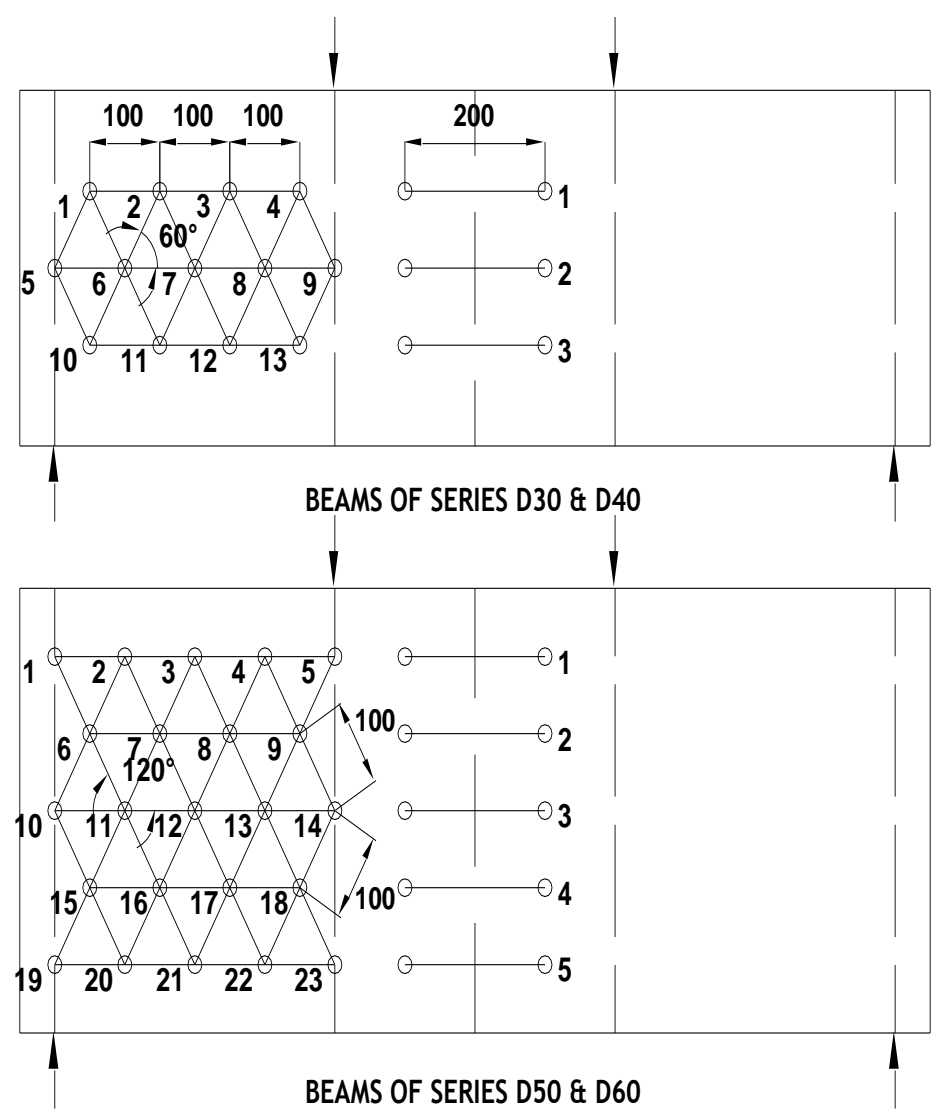

Fig. 3 Hexagonal Grid Arrangement of Demec Targets 


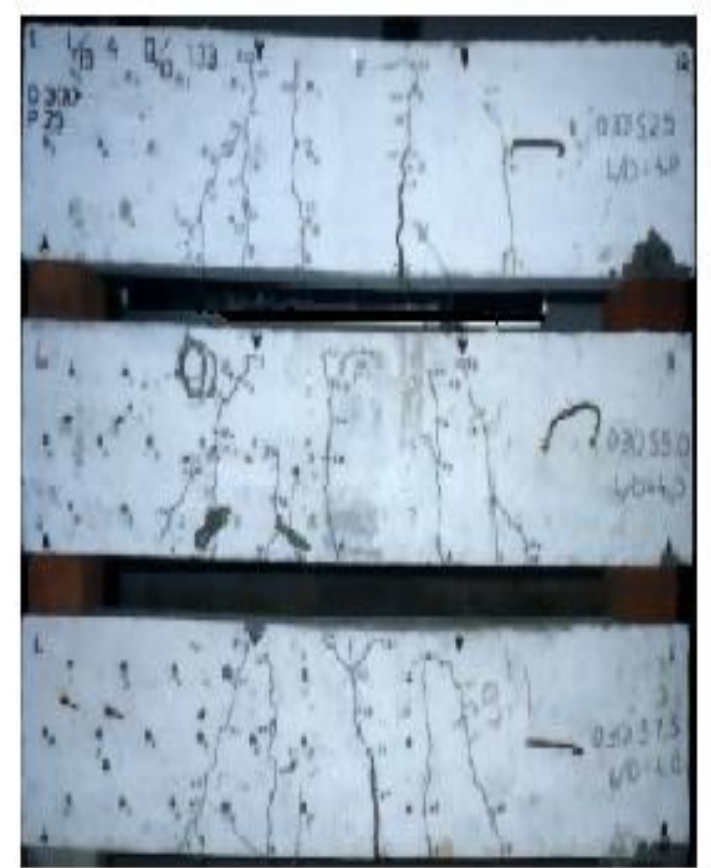

D $308=2.5,5.0,7.5 \mathrm{LD}=4.0$

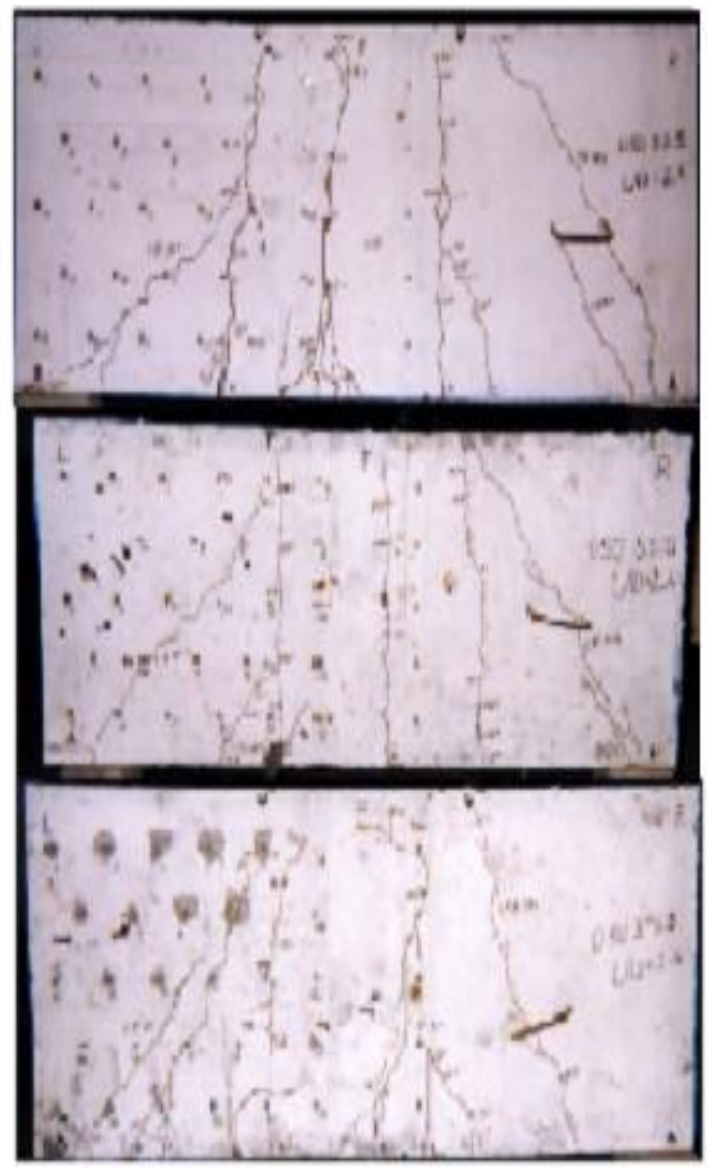

D $50 S=2.5,5.0,7.5 \mathrm{LD}=2.4$

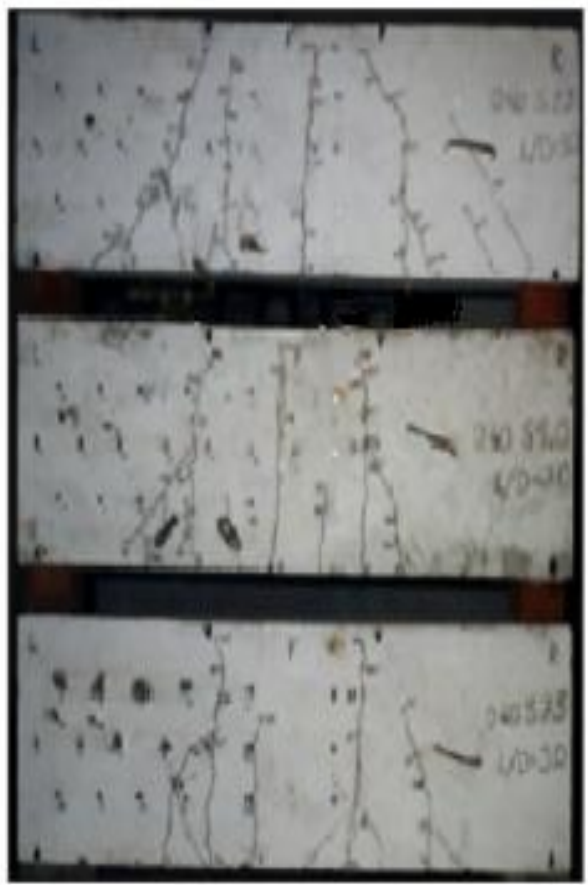

$D 40 S=2.5,5.0,7.5 \mathrm{LD}=3.0$

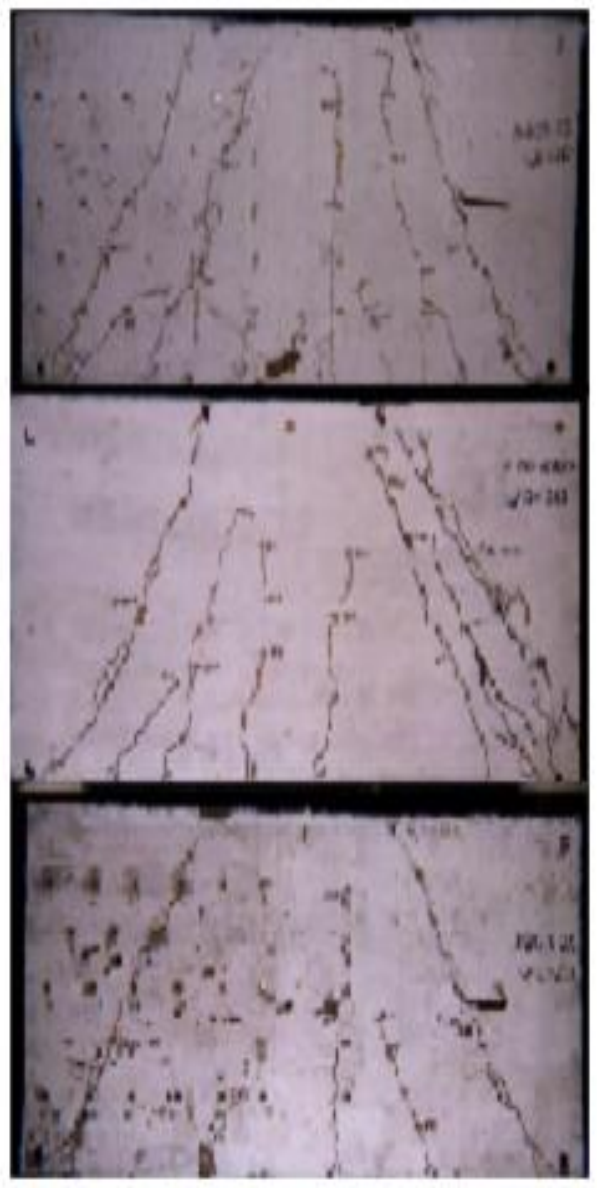

D $608=2.5,5.0,7.5 \mathrm{LD}=2.0$

Fig. 4 Crack Patterns 


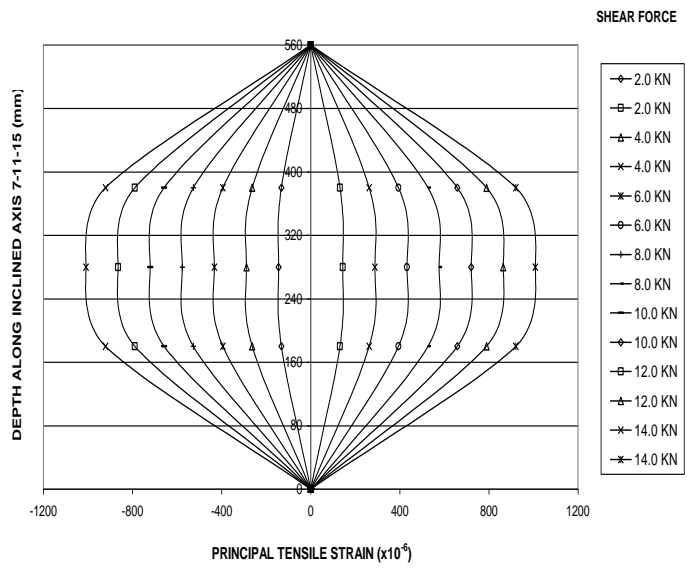

BEAMS OF SERIES D50

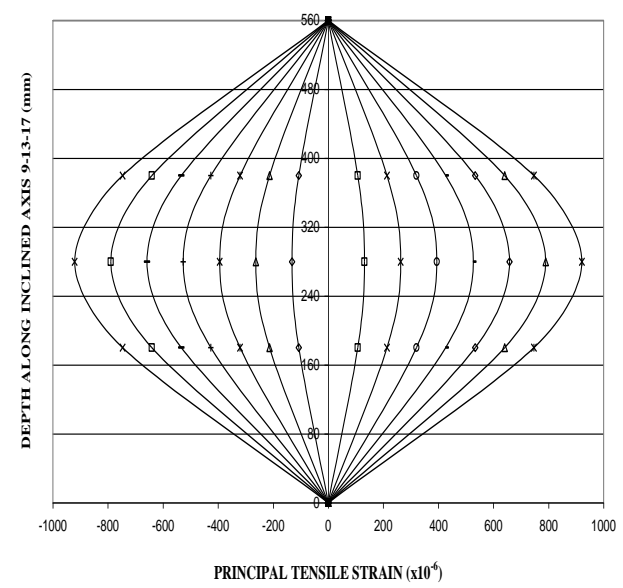

BEAMS OF SERIES D50

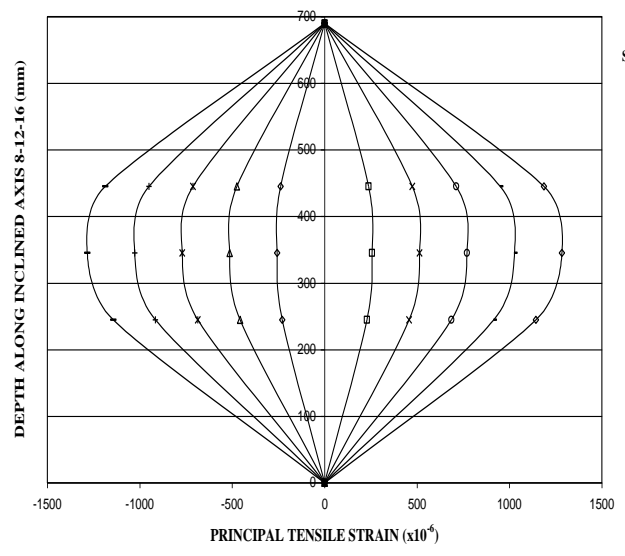

BEAMS OF SERIES D60

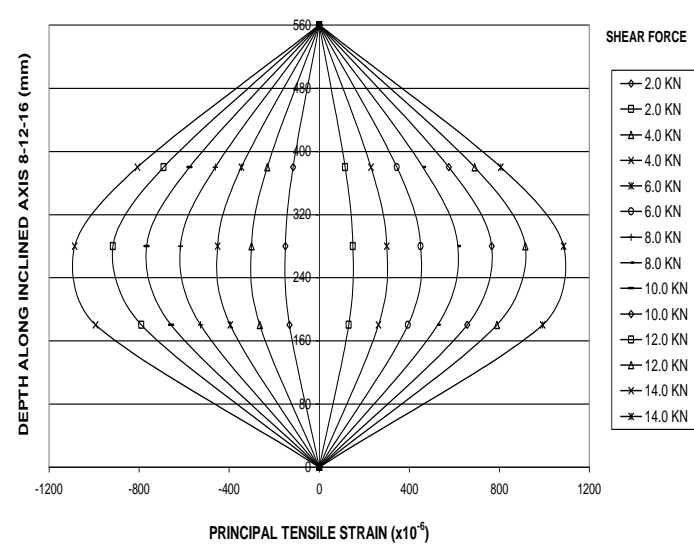

BEAMS OF SERIES D50

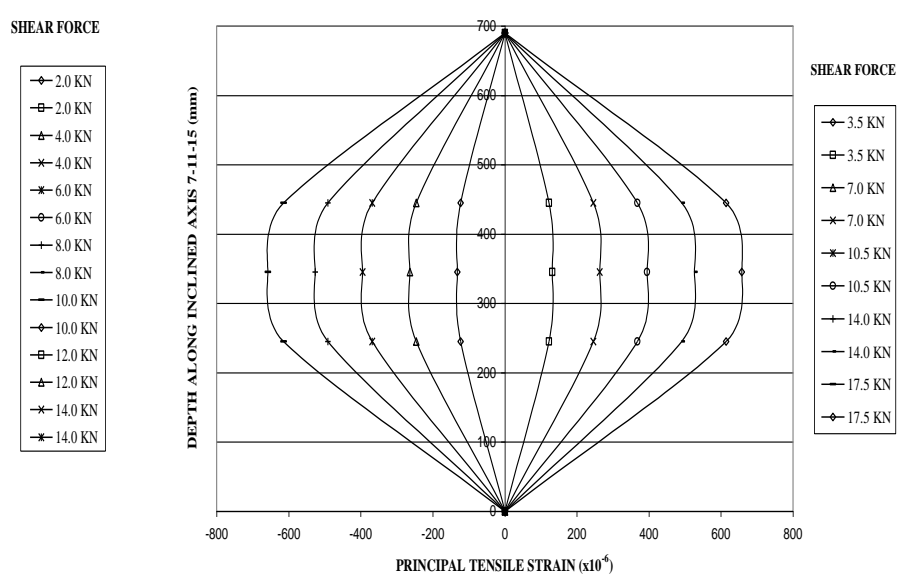

BEAMS OF SERIES D60

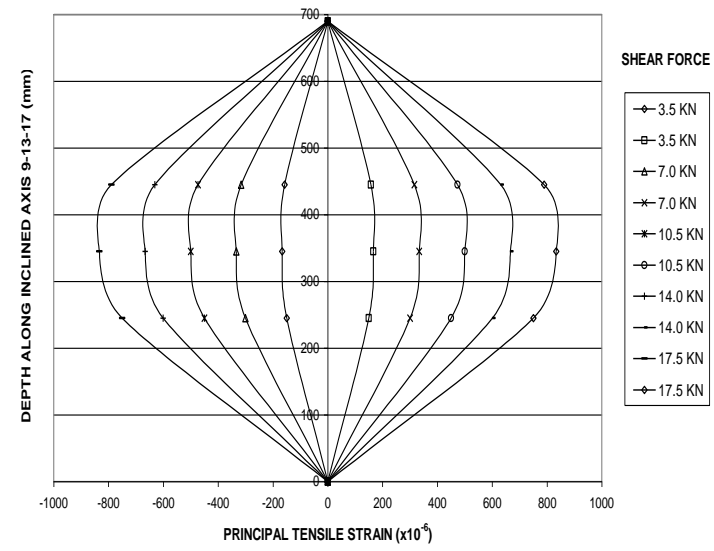

BEAMS OF SERIES D60

Fig. 5 Principal Strain Distributions 